Conf- $940592 \cdots 8$

UCRL-JC-116774

PREPRINT

\title{
Observation of Strong Emission from Ne IX and NeX Transitions in a Laser-Driven Plasma
}

John K. Crane, Todd Ditmire, Hoang Nguyen and Michael D. Perry

This paper was prepared for submittal to the Conference Proceedings of the 4th International

Colloquium on X-ray Lasers

Williamsburg, Virginia

May 16-20, 1994

July 1994

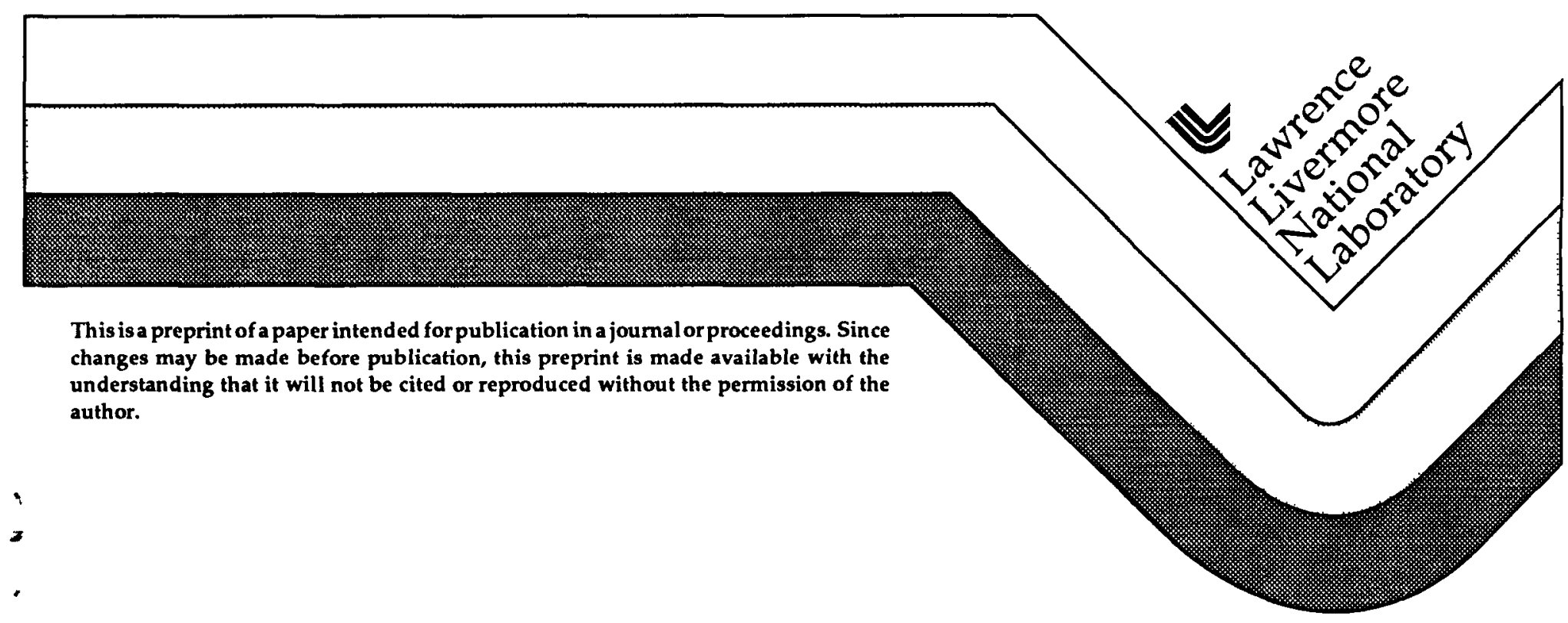

This is a preprint of a paper intend ed for publication in a journal or proceedings. Since changes may be made before publication, this preprint is made available with the understanding that it will not be cited or reproduced without the permission of the author. 


\title{
Observation of Strong Emission from Ne IX and NeX Transitions in a Laser-Driven Plasma
}

\author{
John K. Crane, Todd Ditmire, Hoang Nguyen, and Michael D. Perry \\ Lawrence Livermore National Laboratory, L493, P. O. Box 808, Livermore, CA 94550, U. S. A. \\ Tel: $510-422-0420$ \\ FAX: $510-422-1930$ \\ email: crane1@llnl.gov
}

\begin{abstract}
We observe strong emission from the $1 s^{2}-1$ snp Rydberg series in He-like neon and from the Lyman- $\alpha$ transition in $\mathrm{H}$-like neon. These emissions are observed when $1.05 \mu \mathrm{m}$ light from a 650 femtosecond laser is focussed into the dense, localized output of a pulsed, supersonic nozzle. The maximum focal irradiance of our laser was measured at full power in a vaccum to be $2 \times 10^{18}$ $\mathrm{W} / \mathrm{cm}^{2}$. Although emissions from lower charge states such as $\mathrm{Ne}^{6+}$ and $\mathrm{Ne}^{7+}$ closely follow rates predicted by tunneling theory, emissions from $\mathrm{Ne}^{8+}$ and $\mathrm{Ne}^{9+}$ are observed at irradiances two orders of magnitude below tunneling theory estimates (e.g. the He- $\alpha$ line appears at $2 \times 10^{17} \mathrm{~W} / \mathrm{cm}^{2}$ ). We discuss the origins of these anomalously high charge states and the implications to recombinationpumped $x$-ray lasers.
\end{abstract}

\section{INTRODUCTION}

Recently McPherson et al. ${ }^{1}$ reported strong, energetic emission(greater than 1 $\mathrm{keV}$ ) from laser excited, krypton atoms in a pulsed gas source. Audebert et al. ${ }^{2}$ observed $\mathrm{K} \alpha$ emission from argon in the interaction between a subpicosecond laser and the output of a gas jet. In both cases the emissions are anomalous in the sense that they derive from ions stripped to a higher charge state than predicted by tunneling theory. McPherson et al. postulate that this anomalous emission results from a new type of absorption in the clusters of $\mathrm{Kr}$ atoms, formed in the supersonic expansion of the gas nozzle. Other mechanisms that may cause sufficient excitation to produce these emissions include collisional ionization from the field-driven free electrons, or from the hot electrons produced by stimulated Raman scattering in the plasma. In any case the observation of such strong anomalous emission of a collisional origin will affect the design of ultrashort pulse, recombination pumped XUV lasers that depend on the existence of cold electron temperatures at electron densities of $\sim 10^{19} \mathrm{~cm}^{-3}$. In this paper we present our observations of fluorescence from He-like and $\mathrm{H}$-like neon. We compare our results with a model that combines a laser-driven collisional excitation term with tunneling ionization.

\section{DESCRIPTION}

The laser system used in our experiments is a Nd:glass system that can generate up to 10 Joules at a wavelength, $\lambda=1.053 \mu \mathrm{m} .{ }^{3}$ The system employs chirped pulse amplification to produce high contrast, time-bandwidth limited pulses that are 650 femtoseconds in duration at a power level of $15 \mathrm{TW}$. To determine the focussed irradiance of the laser in vacuum we simultaneously measure the pulse duration, pulse energy and the spatial beam profile at the focus at full laser power. To make x-ray emitting plasmas we focus the laser at the output of a pulsed gas jet that is equipped with a supersonic nozzle designed for Mach 8 flow. To determine the 


\section{DISCLAIMER}

This report was prepared as an account of work sponsored by an agency of the United States Government. Neither the United States Government nor any agency thereof, nor any of their employees, make any warranty, express or implied, or assumes any legal liability or responsibility for the accuracy, completeness, or usefulness of any information, apparatus, product, or process disclosed, or represents that its use would not infringe privately owned rights. Reference herein to any specific commercial product, process, or service by trade name, trademark, manufacturer, or otherwise does not necessarily constitute or imply its endorsement, recommendation, or favoring by the United States Government or any agency thereof. The views and opinions of authors expressed herein do not necessarily state or reflect those of the United States Government or any agency thereof. 


\section{DISCLAIMER}

Portions of this document may be illegible in electronic image products. Images are produced from the best available original document. 


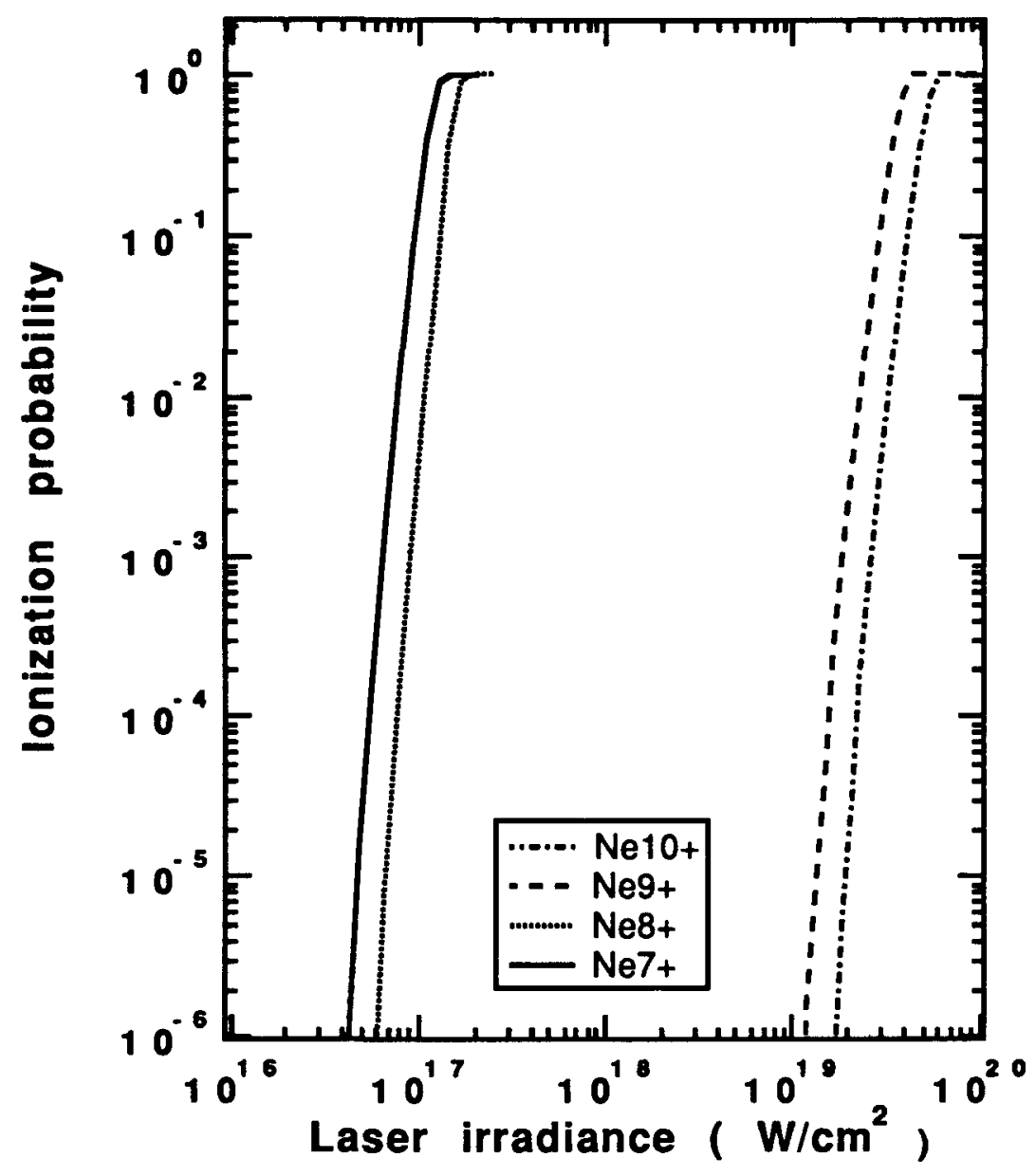

FIGURE 2. Ionization probability versus laser irradiance for higher charge states in neon.

To account for an enhanced rate of ionization necessary to yield $x$-ray line emission from transitions in $\mathrm{Ne}^{8+}$ and $\mathrm{Ne}^{9+}$, we have considered laser field-driven collisional ionization. The number of ions of each charge species produced with the passage of the focused laser pulse is calculated by solving the coupled series of equations for sequential ionization as a function of both space and time. Laser assisted collisional ionization is modeled by including in the rate equations a cycle averaged collisional ionization rate. Only the quiver velocity of the free electrons is considered; all thermal motion is considered negligible compared to the very large quiver motion. If the classical expression for the collisional ionization of a bound electron is used, the cycle averaged collisional ionization rate for the $\mathrm{i}^{\text {th }}$ charge species is given by:

$$
\left\langle\frac{d n_{i+1}}{d t}\right\rangle_{\text {coll }}=\frac{q_{i} e^{4} n_{e} n_{i}}{\sqrt{m U_{p}}}\left[\left(\frac{1}{I_{p}}+\frac{1}{4 U_{p}}\right) \ln \left(\frac{1+\sqrt{1-I_{p} / 2 U_{p}}}{1-\sqrt{1-I_{p} / 2 U_{p}}}\right)-\frac{\sqrt{1-I_{p} / 2 U_{p}}}{I_{p}}\right]
$$


As can be seen in comparing the model results with the emission data, Ne VII and NeVIII emissions are accurately simulated by the model, however the deviation of the model predictions from the observed emissions for the $\mathrm{Ne} \mathrm{IX}$ and $\mathrm{Ne} X$ transitions is significant- these emissions are much stronger than what our simple collisional model would indicate. Recent work at Rutherford7, where similar observations of $\mathrm{H}$-like and He-like emissions in Ne are seen, suggests that Raman heating may produce the necessary density of sufficiently energetic electrons to yield the strong emissions that we observe. We also see strong Raman backscattering in our experiments and are currently developing a similar Raman heating model for use in understanding our results. Alternatively, similar anomalous emissions have been reported by McPherson in $\mathrm{Kr}$ and $\mathrm{Xe}$ and are attributed to collective electron effects in the large clusters that are generated by their supersonic nozzle. Under the conditions of operation of our pulsed supersonic nozzle (Mach 8 flow) we are also likely to be producing large clusters of neon atoms 8 , however, until we can obtain more quantitative evidence for a cluster-based mechanism to explain our results we will continue to focus our attention on the Raman-based mechanism for producing anomalous $\mathrm{x}$-ray emission.

\section{SUMMARY}

We observe anomalous $\mathrm{x}$-ray emission from $\mathrm{He}$ and $\mathrm{H}$-like transitions in neon plasmas produced from a gas jet. We see these emissions at focal irradiances that are two-orders of magnitude below the values that would be predicted by a purely field ionization mechanism.Although preliminary estimates for collisional excitation from field driven electrons yield a substantial enhancement of the rates over a pure tunneling mechanism they fail to predict the large yields that we observe experimentally. We continue in investigate other mechanisms to explain the bright line emissions from $\mathrm{NeIX}$ and $\mathrm{NeX}$ transitions in laser driven plasmas produced from gaseous targets.

\section{References:}

1. McPherson, A., Luk, T. S., Thompson, B. D., Borisov, A. B., Shiryaev, O. B., Chen, X., Boyer, K., and Rhodes, C. K., Phys. Rev. Lett. 72, 1810-1813 (1994).

2. Audebert, P. et al., "X-ray emission from an Ar gas jet induced by an intense femtosecond laser pulse", presented at the Conference on Generation and Application of Ultrashort X-Ray Pulses, Salamanca, Spain (1994).

3. Patterson, F. G., Perry, M. D., and Hunt, J. T., J. Opt. Soc. Am B 8, 23842390 (1991).

4. M. D. Perry, C. B. Darrow, C. Coverdale, and J. K. Crane, Opt. Lett. 17, 523525 (1992).

5. Ammosov, M. V., Delone, N. B., and Krainov, V. P., Sov. Phys. JETP 64, 1191-1194 (1986).

6. Augst, S., Meyerhofer, D. D., Strickland, D., and Chin, S. L., J. Opt. Soc. $A m B$ 8, 858-867 (1991).

7. Keys, M. H.,"Reduction of driver energy for X-ray lasers," presented at the 4th International Conference on X-Ray Lasers, Williamsburg VA, May 16-20, 1994.

8. Hagena, O. F., Obert, W., J. Chem. Phys 56, 1793-1802 (1972).

This work was performed under the auspices of the United States Department of Energy by the Lawrence Livermore National Laboratory under contract no. W-7405-Eng-48. 